\title{
Financial Viability of PCMs in Countries with Low Energy Cost: A Case Study of Different Climates in Iran
}

\author{
Ebrahim Solgi ${ }^{a}$, Sina Memarian ${ }^{b,}{ }^{*}$, Ghazaleh Nemati Moud ${ }^{c}$ \\ ${ }^{a}$ Department of Architecture, School of Engineering and Built Environment, Griffith University, Australia. \\ ${ }^{\mathrm{b}}$ Department of Architecture and Energy, University of Art, Iran. \\ ${ }^{c}$ Department of Architecture and Energy, University of Tehran, Iran. \\ ${ }^{*}$ Corresponding author: e-mail: sina.memarian@yahoo.com
}

\begin{abstract}
Properties of desirable weight, latent heat capacity, and energy storage capability of phase change materials (PCMs) have led to extensive use of these materials in the building industry as productive thermal mass. This study investigated the feasibility of the utilization of PCMs through numerical simulations in residential buildings located in different Iranian climates in Tehran, Tabriz, Yazd, and Bandar Abbas. In so doing, the optimal PCM for each city was selected based on its impact on annual energy consumption, and then its effects on the indoor temperature and thermal load of the model in the hottest and coldest months of the year were examined. The results showed that the use of PCMs does not lead to significant energy conservation in the hot and humid climate of Bandar Abbas compared with other climates. In the second part of the study, the economic feasibility of PCMs and the payback period of such investment were investigated based on the current local electricity and natural gas prices. It was found that although the use of PCMs leads to significant energy conservation in most of these climates, with the current prices of energy and PCMs in Iran, the use of these materials will not be cost-effective, as the return periods for such investment in Tehran, Tabriz, Yazd, and Bandar Abbas will be 42, 179, 102, and 114 years, respectively.
\end{abstract}

Keywords: Phase change Materials, PCMs, Energy Storage, Economic Analysis, Passive Design 


\section{Introduction}

According to the U.S. Energy Information Administration [1], energy consumed in residential and commercial buildings accounts for $20.1 \%$ of the total delivered energy in the period of 2012 to 2040. It is also predicted that this ratio will see a $1.5 \%$ annual increase globally and $2.1 \%$ annual increase in non-OECD countries. More than one-third of the energy consumed in buildings is for heating and cooling purposes [2]. One of the main components of energy conservation in buildings is the building envelope, the design and construction of which can have a 20-60\% impact on energy consumption [3]. According to Sadineni et al. [3], there are two strategies for optimizing energy consumption in buildings. Active strategies include the optimization of HVAC and artificial lighting systems, and passive strategies include the optimization of the building envelope to reduce energy demand. One of the main passive strategies of energy conservation is the use of Thermal Energy Storage (TES) and thermal inertia for maintaining desired indoor thermal comfort and reducing the energy demand of the building [4-7]. Past studies have demonstrated the significant impact of thermal inertia on the thermodynamic behavior of buildings and recommended the use of PCMs as one of the main ways of utilizing thermal inertia to achieve energy conservation in buildings $[8,9]$.

Research has shown that PCMs can reduce cooling load by reducing internal temperature fluctuations [10-15], and shifting the heating and cooling load from high-peak to off-peak periods [16, 17]. It is known that using a PCM with a melting temperature close to the comfort zone can reduce peak indoor temperature, prolong the period when the indoor temperature remains within the comfort zone, and reduce the energy demand and hence the energy bill [18]. PCMs can be used in HVAC systems actively such as cylinder tanks $[19,20]$ and heat pumps for space heating or cooling [21, 22]. Some studies have investigated the performance of energy storage tanks and the influence of different geometric and thermal parameters on PCM melting time, based on PCM types and tank configurations, and these studies have also performed economic assessments in relation to renewable energy systems $[23,24]$.

Numerical modeling can serve as a powerful method for evaluating the application of PCMs in building [25, 26]. Lei et al. [27] evaluated the energy performance of a building envelope integrated with $10 \mathrm{~mm}-\mathrm{PCM}$ in the tropical climate of Singapore. This study showed that the use of PCMs reduces the annual heat gain through the building envelope by about $21-32 \%$. In addition, the best performance was achieved by the use of PCMs at the outer surface of the wall, which resulted in highest efficiency and cost-effectiveness. Jin and Zhang [28] used numerical modeling to analyze the thermal efficiency of two layers of PCMs that are integrated into the building floor. They used two PCM layers with different melting temperatures to store energy in the off-peak hours and release it in the peak hours. The study found that the optimum melting temperatures for heating and cooling were $38^{\circ} \mathrm{C}$ and $18^{\circ} \mathrm{C}$ respectively. It was concluded that, compared to an ordinary floor, a floor that is equipped with two layers of PCMs can release about $41.1 \%$ and $37.9 \%$ more energy during heating and cooling periods, respectively. Kenisirin and Mahkamov's studying [29] searched for the desirable melting temperatures of PCMs in residential buildings. With the room conditions assumed, based on a comfort range of $18-25^{\circ} \mathrm{C}$, they found that the desirable PCM melting temperature for passive systems were about $13-32^{\circ} \mathrm{C}$.

In a study conducted by Saffari et al. [30], the optimal PCM melting temperature in residential buildings in different climates was determined through numerical simulation according to the World Map of Köppen-Geiger climate classification. The results showed that 
the optimal PCM melting temperature is about $26^{\circ} \mathrm{C}$ (in the range of $24-28^{\circ} \mathrm{C}$ ) for cooling dominant climates and about $20^{\circ} \mathrm{C}$ (in the range of $18-22^{\circ} \mathrm{C}$ ) for heating dominant climates, and that for the climates with different Cooling Degree Days (CDD) and Heating Degree Days (HDDs), the optimal melting temperature can be between the lowest and the highest peak melting temperatures. In another analysis, Saffari et al. [31] used the EnergyPlus software to evaluate the impact of integration of PCMs into a building in the Madrid climate with the effect of melting temperature, thickness and payback period taken into consideration. Their results showed that given the operational schedule of office and residential buildings, the highest annual energy conservation can be achieved by the use of a PCM with a melting temperature of $27^{\circ} \mathrm{C}$, and a thickness of $10 \mathrm{~mm}$ for residential buildings and $5 \mathrm{~mm}$ for office buildings. Also, payback time was found to be less than 2-3 years for residential buildings and about 6 years for office buildings. The optimal PCM melting temperatures that result in the highest energy conservation in summers and winters were found to be $27^{\circ} \mathrm{C}$ and $23^{\circ} \mathrm{C}$ respectively.

In an experimental study on two identical rooms with PCM impregnated gypsum boards, it was found that using PCMs with an undesirable control strategy may increase the energy demand of air-conditioning [32]. To improve energy storage, this study proposed the combined use of night ventilation and free cooling to discharge PCMs, as opposed utilizing air conditioning. It was reported that this approach leads to $73 \%$ electricity conservation over a 1-week period and 93\% energy conservation and 92\% cost saving over a 1-day period. Barzin et al. [33] conducted an experimental study on two rooms, one with an ordinary gypsum board finishing and the other with PCM impregnated gypsum boards, using the price-base control method. The results showed that with the climate conditions taken into account, the room with PCM achieved energy and cost savings as high as $90 \%$ over a day and $40 \%$ over an 11-day period. Zhu et al. [34] examined the effect of integration of shapestabilized phase change material (SSPCM) into the envelope of office buildings in Hong Kong and Beijing, using time-based pricing and energy-plus-demand-based pricing policies. Their results showed that based on the time-based policy, this approach will lead to $11.44 \%$ and $11.29 \%$ reduction in the daily electricity cost of building in Hong Kong and Beijing, but based on the energy-plus-demand-based policy, these values will be $10.61 \%$ and $12.76 \%$ respectively.

Chan et al. [35] used the EnergyPlus software to simulate and study a conventional Hong Kong residential unit with PCMs integrated into the outer wall of the living room and bedroom. The results showed that this approach results in $2.9 \%$ and $1 \%$ annual cooling energy conservation for the living room and the bedroom respectively. The cost payback period was calculated to about 91 years, and the energy payback period was found to be about 23.4 years. The authors also reported that since PCMs had a melting temperature of $21.7^{\circ} \mathrm{C}$ but the wall surface had a temperature of more than $28^{\circ} \mathrm{C}$, PCMs were not able to effectively absorb heat and release it at night. Thus, this climate requires the use of PCMs with a higher melting temperature. Sun et al. [36] conducted an energy and economic analysis on the application of PCM in buildings during the cooling season. This study found that a $100 \%$ saving in cooling energy and $13.1 \%$ average saving in electrical energy is achievable. The shortest and longest simple payback periods (SPP) were found to be 5.99 and 8.20 years for Kunming and Changsha, respectively. It was found that the optimal phase change temperature for achieving an acceptable SPP is $3^{\circ} \mathrm{C}$ above the average outdoor temperature. The energy and economic performance of a PCM integrated building in five cities in China was by Mi et al. [37]. In this study, PCMs were assumed to have a melting temperature of 
$27^{\circ} \mathrm{C}$, and simulations were performed using the EnergyPlus software. The best energy savings were obtained for the Shenyang area (very cold climate), Zhengzhou area (cold climate), and Changsha area (hot summer - cold winter climate), with static payback periods of 5-7 years. This study reported that investments in PCM in these areas is cost-effective, but will not be economical in Hong Kong and Kunming.

According to Shilei et al. [38], integration of PCMs into the walls can reduce the cost of HVAC systems by shifting the peak load and filling the consumption valley. An article published by Shi et al. [39] reported that the integration of macro-encapsulated PCMs into concrete walls in a realistic room model led to the smoothing of fluctuations and shifting of energy load away from peak time, which means energy can be bought at lower prices in the off-peak periods. This study also investigated the use of PCMs in an ordinary residential unit in the Hong Kong climate, and found that the payback period of such projects will be about 11 years. Stovall and Tomlinson [40] analyzed the use of PCM wallboards in a solar passive system, and reported that this approach leads to an energy saving with a payback period of about 3-5 years. Kosny et al. [41] studied the performance of dispersed PCMs and estimated a payback period of shorter than 10 years for the use of these materials in the roof and walls. In another study, Peippo et al. [42] investigated the use of PCM impregnated gypsum board in a passive solar building, and reported an annual energy saving of $15 \%$ for Madison and $6 \%$ for Helsinki, as well as simple payback time of 10 and 20 years for Madison and Helsinki respectively. Zalba et al. [43] evaluated the overall cost of free cooling systems, and reported that PCM constitutes about $17 \%$ of the total cost of such a system. In a comparison between the storage system $(\mathrm{PCM})$ and the conventional refrigeration system, they found that the PCM system requires $9 \%$ more investment, has a 3 to 4 year shorter payback period, and 9.4 times lower electricity consumption.

In Iran where the issue of using lightweight structures has recently received considerable attention, the implied resulting lack of sufficient and productive thermal mass means that the employment of PCMs as lightweight thermal energy storage is an attractive proposition [44]. However, there is not adequate information regarding the amount of energy conservation from the application of these materials based on the Iranian building codes, which has particular HVAC set-points for its different climates. It is also imperative to note that the energy tariff in Iran is relatively low compared to other countries, and the way that the energy price (both gas \& electricity) is calculated because of subsidies is exceptional. To date, there has been no economic analysis of the use of these materials in the different climates of Iran based on the local prices of energy carriers for heating and cooling. Therefore, this study set out to investigate the effect of optimal PCMs on total energy saving and indoor thermal conditions in addition to their economic efficiency in different climates zones. To do so, in this study, we/first determine the optimal PCMs for multiple climates within Iranian territory, then examine their effect on energy conservation and average indoor temperature, and finally perform an economic analysis on the use of these materials based on the price of natural gas and electricity.

\section{Methodology}

Due to there being no PCM implementations in Iran to date and a lack of laboratory equipment, there was no possibility of field measurements in all four existing climates. This study therefore is conducted with EnergyPlus software version 8.3 which enables users to simulate the parameters of PCMs by virtue of the "Conduction Finite Difference (CFD)" algorithm utilized to simulate the impact of PCMs. Furthermore, as the purpose of the 
research is to understand the efficacy of PCMs in different locations and the resultant heating/cooling load differences, along with the financial saving, a representative single zone model is sufficient. Thus, in this research, the 600 case, which is a lightweight model, from the Building Thermal Envelope and Fabric Load Tests series of the ANSI/ASHRAE Standard 140-2014 (based on BESTEST) is considered as the qualified case [45]. The room studied in this study has dimensions of $8 \times 6 \times 2.7 \mathrm{~m}$ and the zone air volume is $129.6 \mathrm{~m} 3$. The southern wall of the model is supplied with two double-glazed windows which have $3 \times 2 \mathrm{~m}$ dimensions. The case has a 200 -watt internal gain, and an infiltration rate of $0.5 \mathrm{ACH}$ (air changes per hour). The roof and four walls are specified as the exterior surfaces exposed to ambient air; Table 1 provides a detailed description of the structure of the envelope utilized in the model, as well as the order and arrangement of the building materials. In order to reduce uncertainty concerning testing the other facets of simulating the building envelope, the floor insulation described in Table 1 has also been made very thick (approximately 1 meter) to efficaciously de-couple the floor from the ground in point of thermal considerations. It should be noted that the PCM used for the study is energy blankets (BioPCM) with a thickness of 1 $\mathrm{cm}$ [46], and the solar reflectance of the site ground surface is 0.2 . This model will be applied for analysis in four cities namely Tehran, Tabriz, Yazd and Bandar Abbas, which vary in climate. Climatic characteristics of the aforementioned cities are presented in Fig. 1. It is imperative to note the thermostat cooling and heating set-points were set according to Building Code No. 19 of Iran, which are $20^{\circ} \mathrm{C}$ and $28^{\circ} \mathrm{C}$ for the hot-humid climate of Bandar Abbas and $20^{\circ} \mathrm{C}$ and $25^{\circ} \mathrm{C}$ for other climates, respectively [ 47$]$.

Table 1. Specifications of the building elements [45]

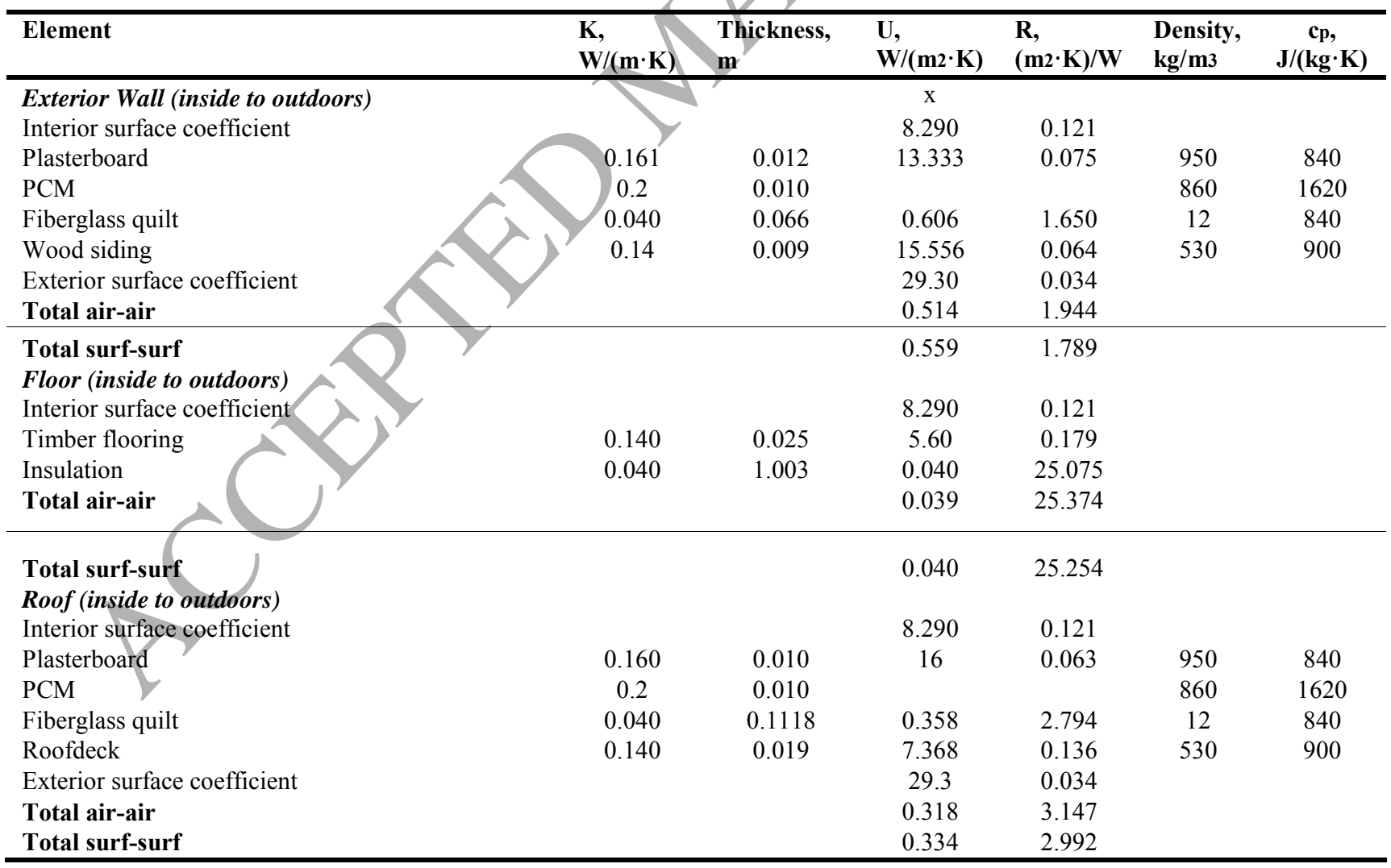



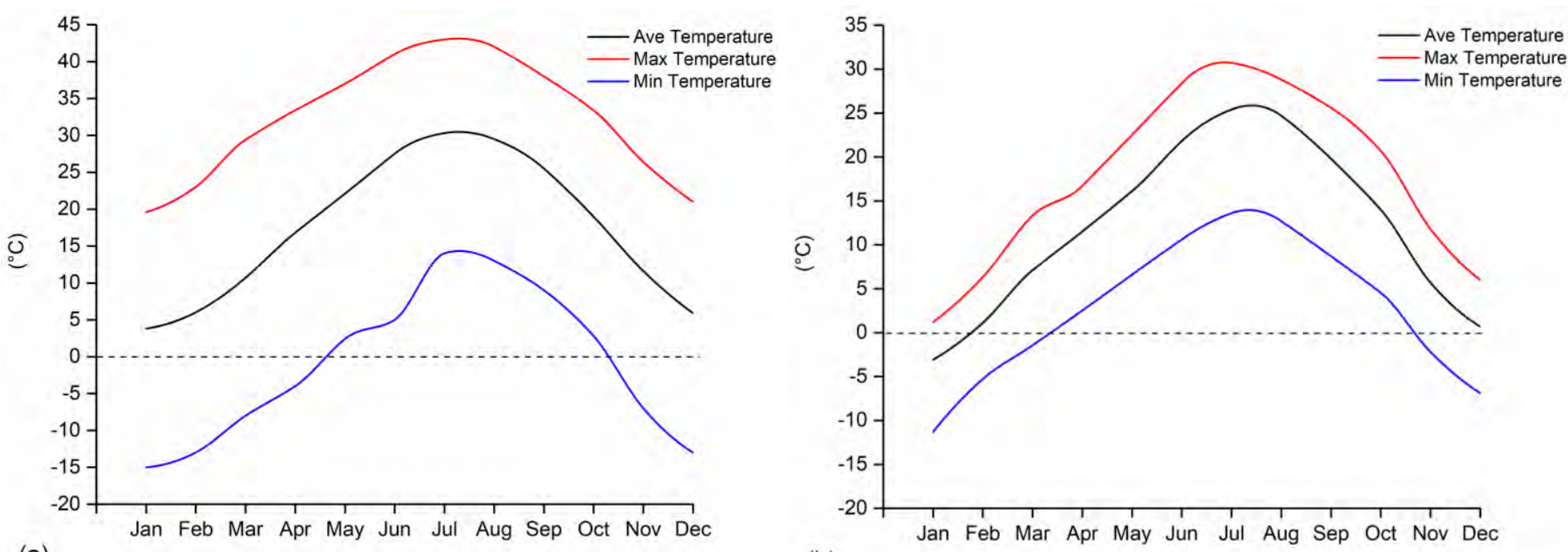

(a)

(b)
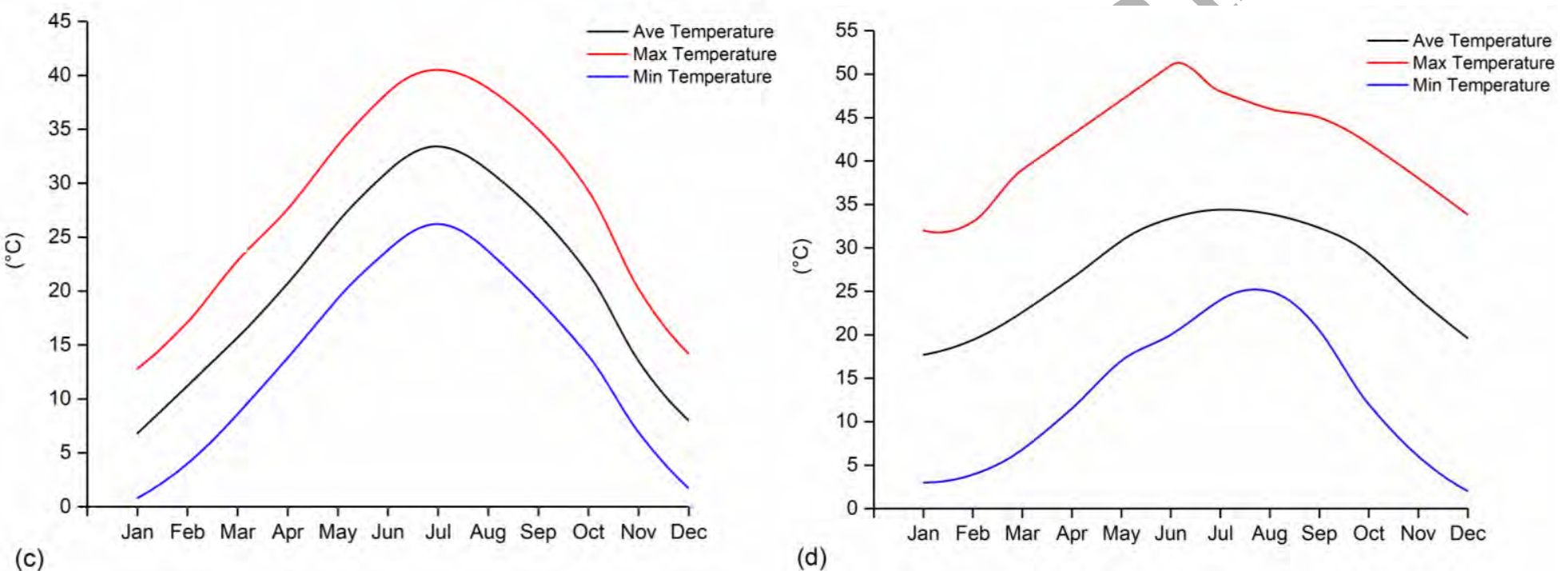

Fig 1. Average monthly weather data of (a) Tehran, (b) Tabriz, (c) Yazd, (d) Bandar Abbas [48]

\section{Results and Discussions}

\subsection{Optimal PCMs}

This section examines the impact of PCMs with melting temperatures of 19, 21, 23, 25, 27, and $29^{\circ} \mathrm{C}$ on annual energy consumption and conservation in four cities in Iran. As shown in Fig. 2, for Tehran, the cooling load (7002.2 $\mathrm{kWh})$ is about 4 times the heating load $(1827.78$ $\mathrm{kWh}$, and in the best case scenario, the use of PCMs with a melting temperature of $29^{\circ} \mathrm{C}$ can reduce the total energy consumption by $2969.5 \mathrm{kWh}$ or $34 \%$. Notably, since in this climate the major application of PCMs is for reducing cooling loads, the PCM with the transition temperature of $29^{\circ} \mathrm{C}$, which is close to the cooling set-point temperature $\left(28^{\circ} \mathrm{C}\right)$, has been the most efficient type. Thus, in this condition, HVAC systems are activated when the liquefaction process reaches close to the maximum set-point temperature, thereby optimizing PCM capability. However, in the cold climate of Tabriz, the main load belongs to heating $(4218.60 \mathrm{kWh})$, and in the best case scenario, the use of PCMs with a melting temperature of $19^{\circ} \mathrm{C}$ will reduce the heating load and the total energy consumption by $22 \%$ and $20 \%$ respectively. Thus, in order to make the most of PCM potential in reducing heating loads, the 
PCM with the transition temperature of $19^{\circ} \mathrm{C}$, which is $1{ }^{\circ} \mathrm{C}$ less than the heating set-point temperature $\left(20^{\circ} \mathrm{C}\right)$, has been optimal, such that in this condition HVAC systems are activated when the solidification process reaches close to the minimum set-point temperature. Conversely, in the hot and dry climate of Yazd, it is the cooling load (6638.8 $\mathrm{kWh})$ that constitutes the major portion of total energy consumption. For this city, the use of optimal PCMs with a melting temperature of $29^{\circ} \mathrm{C}$ will result in a $32.2 \%$ decrease in the total energy consumption and $1800.73 \mathrm{kWh}$ decrease in cooling load. Therefore, just as Tehran reduce its dominant cooling loads in spring and summer, the use of PCMs with the transition temperature of $1{ }^{\circ} \mathrm{C}$ higher than the cooling set-point temperature is also energy-efficient.

In the port city of Bandar Abbas, only a small portion of total energy consumption is dedicated to heating $(151.9 \mathrm{kWh})$, as the dominant part of consumption $(10185.72 \mathrm{kWh})$ is related to cooling during hot seasons. For this city, in the best case scenario, using a PCM with a melting temperature of $27^{\circ} \mathrm{C}$ can reduce the total energy consumption by about $10.9 \%$, of which about $10 \%$ is related to cooling. Interestingly, for this climate the cooling set-point temperature, which is $25^{\circ} \mathrm{C}$, is lower than other climates, the optimal phase change temperature is also lower than other climates. Thus, the most striking result to emerge from the data is that the optimal phase change temperature is contingent upon both HVAC setpoint temperatures and climates. In conclusion, the figures indicate) the highest energy conservation efficiency for Tehran, Tabriz, Yazd and Bandar Abbas can be achieved by the use of $\mathrm{PCM}-29^{\circ} \mathrm{C}, \mathrm{PCM}-19^{\circ} \mathrm{C}, \mathrm{PCM}-29^{\circ} \mathrm{C}$ and $\mathrm{PCM}-27^{\circ} \mathrm{C}$ respectively. In the following sections, these PCMs are selected for consideration as the optimal choice for the respective cities.

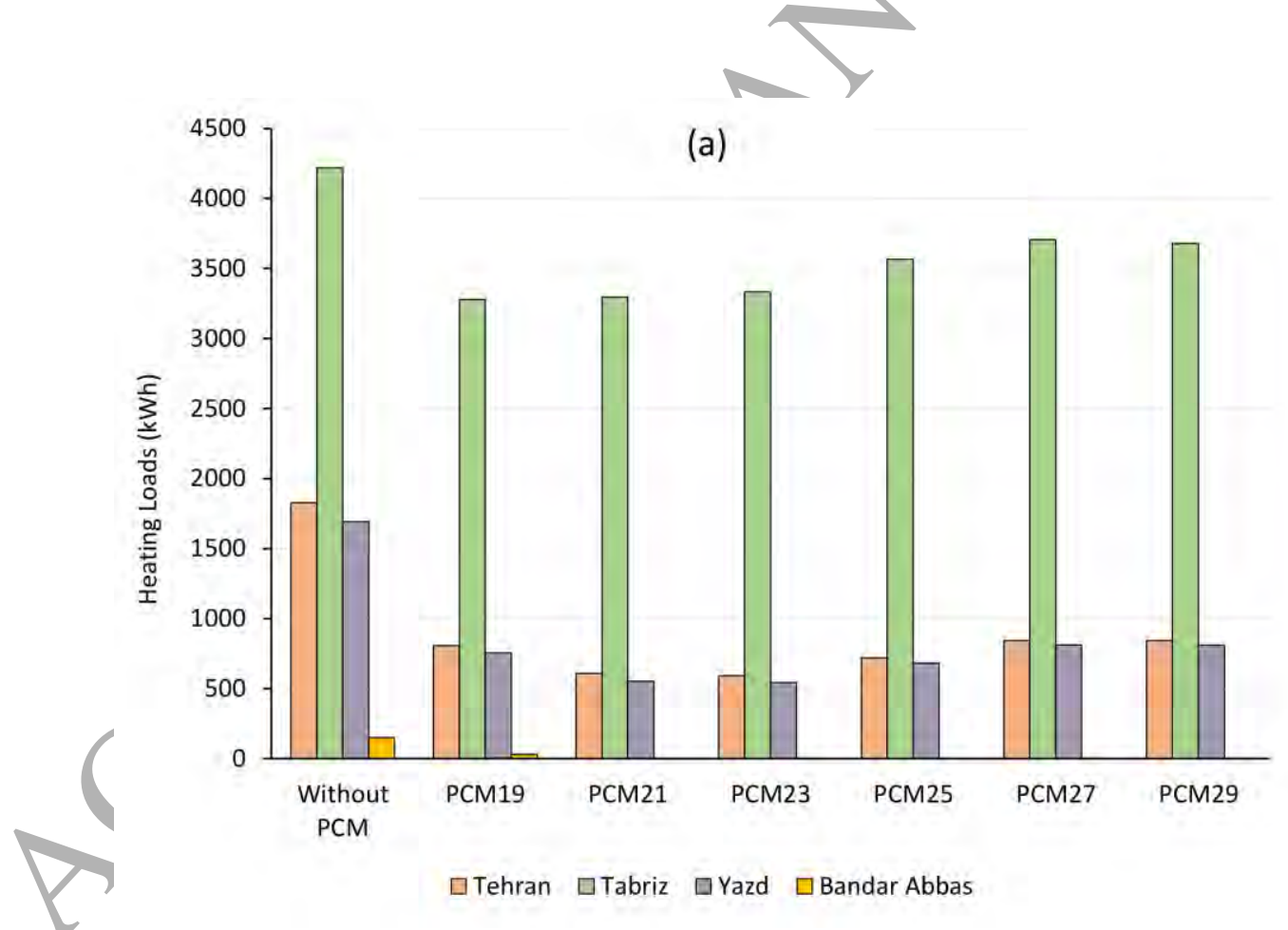




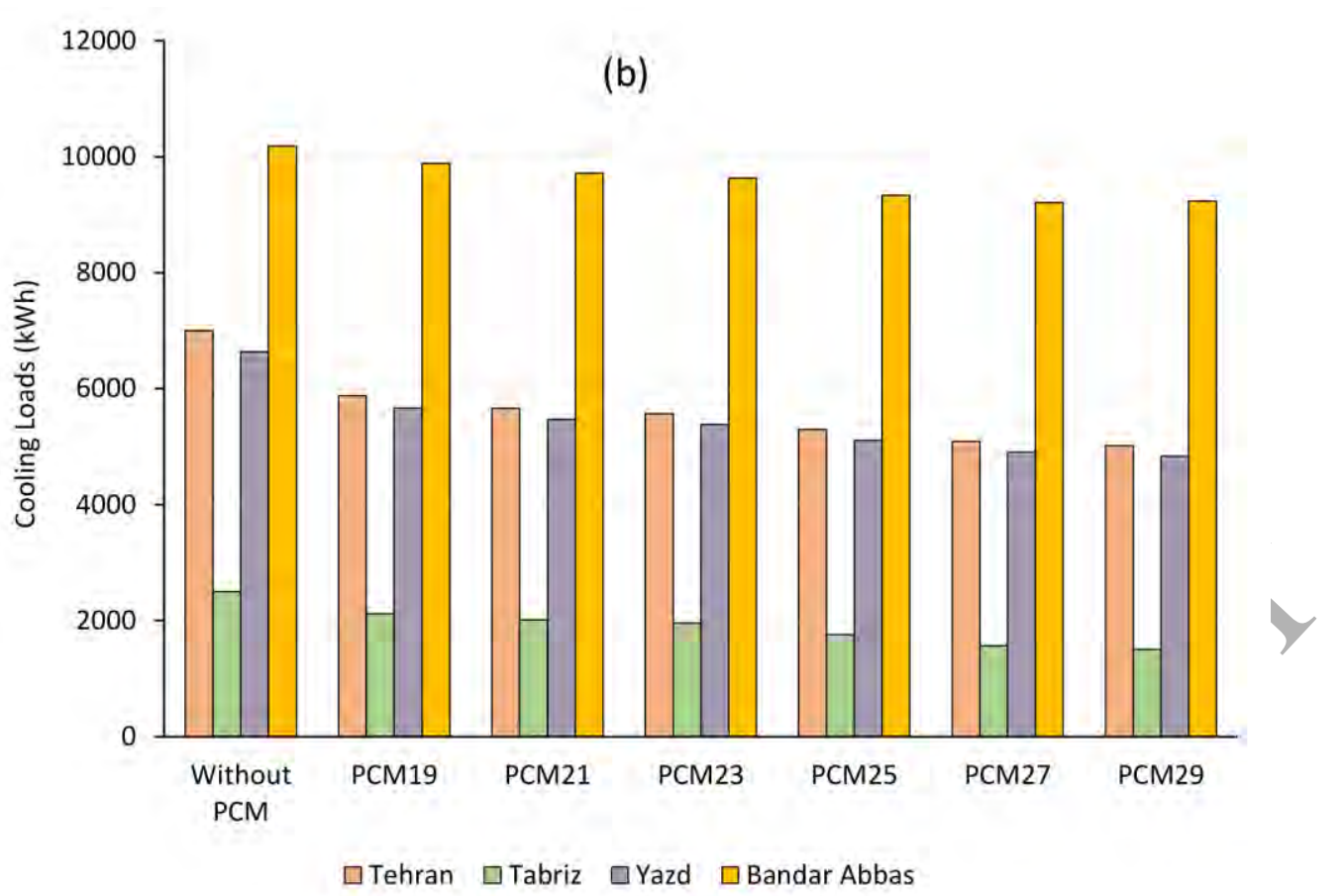

Fig 2: The impact of PCMs' melting temperature on the annual (a) heating and cooling (b) loads of the model

\subsection{Impact of optimal PCMs on monthly heating and cooling loads}

This section explores the effect of optimal PCM on monthly heating and cooling loads. As shown in Fig. 3, although the highest heating and cooling loads in Tehran (Fig. 3a) belong to the months of Jan and Aug, the greatest impact of $\mathrm{PCM}-29^{\circ} \mathrm{C}$ on these loads is in Feb $(50 \%$ reduction) and Aug (48\% reduction). The principal reason for this noticeable cooling load saving of Aug is that during this month ambient temperature conditions are within the range of the PCM transition temperature; as a consequence, the deployment of these materials can noticeably reduce the need for HVAC systems. The hottest month for this city is Jul with an average temperature of $30.3^{\circ} \mathrm{C}$, but the impact of PCM on the load of this month is only 41 $\mathrm{kWh}$ or $5.1 \%$. Notably, during this month, the outdoor temperature in most hours of the day exceeds the phase change temperature of PCM; however, in cooler months such as May, the decrease in cooling load reaches as high as $32 \%$. In Tabriz (Fig. 3b), $\mathrm{PCM}-19^{\circ} \mathrm{C}$ has the highest impact on cooling and heating loads in the months of Nov and Oct that is, 191.4 and $108.4 \mathrm{kWh}$ or $31 \%$ and $44 \%$ respectively. In comparison, the impact of $\mathrm{PCM}-19^{\circ} \mathrm{C}$ on the heating load in the coldest month of the year, i.e. Jan with an average temperature of $-1.7^{\circ} \mathrm{C}$, is just $4.9 \%$. The cause of this meager impact is the outdoor temperature being lower than the PCM transition temperature $\left(19^{\circ} \mathrm{C}\right)$ in the majority of hours on the day. In contrast, in warmer months such as Mar, the reduction in heating load is as high as $31 \%$.

In the case of the deployment of PCM- $29^{\circ} \mathrm{C}$ in Yazd (Fig. 3c), the increase in thermal mass results in 3 more months having a heating load. In Jan, with the highest heating load, using this PCM leads to $27 \%$ reduction in heating load. In the warmest month of the year, i.e. Jul with an average temperature of $32^{\circ} \mathrm{C}, \mathrm{PCM}-29^{\circ} \mathrm{C}$ can reduce the cooling load by just $4 \%$, but in cooler months such as May (when temperature conveniently matches the phase change temperature in more hours of the day), cooling load can be decreased by up to $17 \%$. The use of PCM- $27^{\circ} \mathrm{C}$ in Bandar Abbas (Fig. 3d) completely eliminates its already negligible heating load throughout the entire year. For this port city, this PCM will have the greatest impact on the energy load in Jan and Dec, by reducing the corresponding cooling loads by about $50 \%$. However, in the months between May and Oct, when the temperature is almost always above 
$30^{\circ} \mathrm{C}$, PCM will not have a significant impact on the cooling load. The main reason for the low productivity of these materials in this climate in reducing its dominant cooling loads as opposed to the aforementioned climates is that during hot nights, high ambient temperatures prevent PCMs from losing stored heat, and consequently the solidifying process fails; thus, PCMs cannot be optimized. In stark contrast, however, in the hot dry climate of Yazd owing to cold nights in summer, PCMs usually solidify; therefore, this phenomenon can considerably optimize the PCM capability in reducing cooling loads.
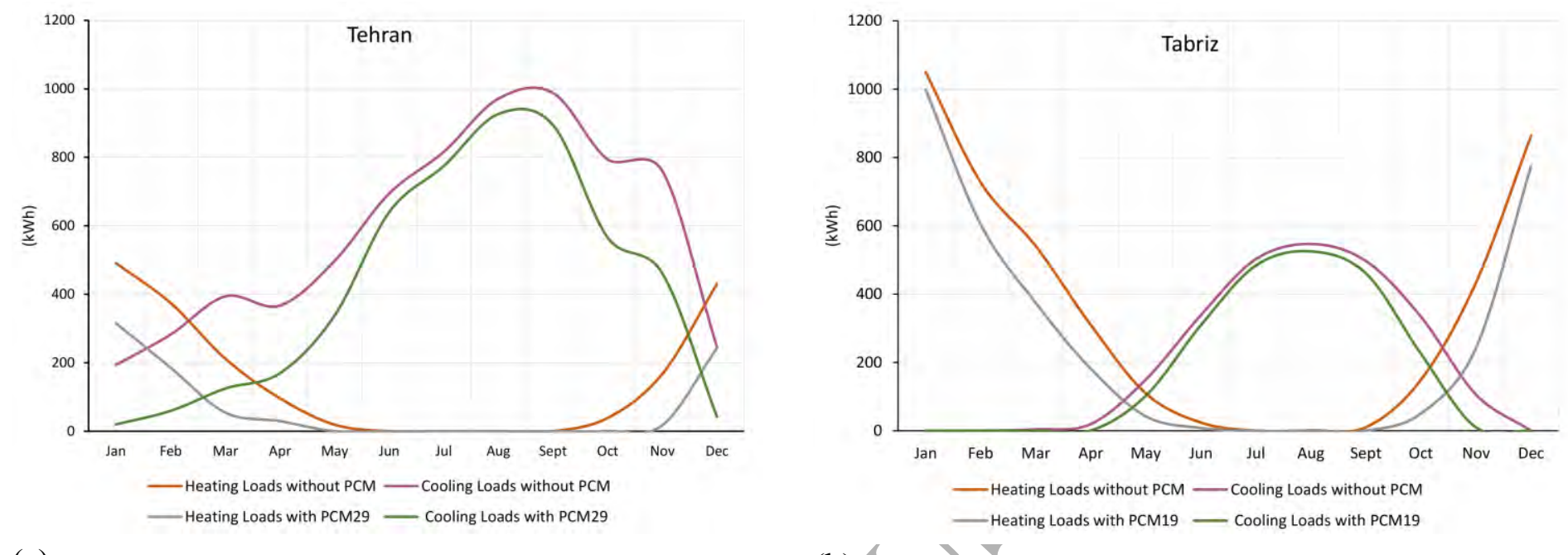

(a)

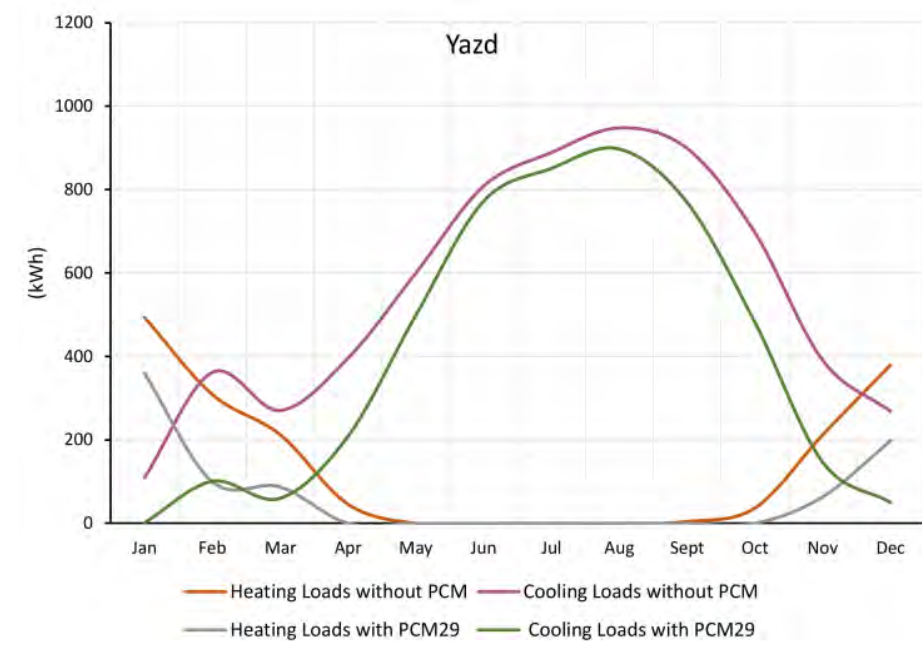

(b)

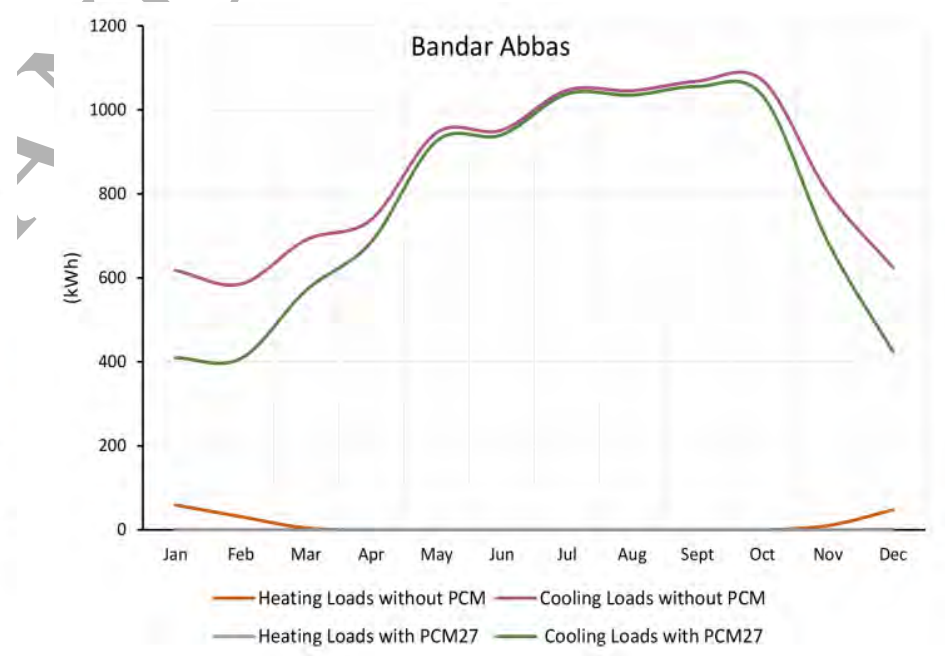

(c)

(d)

Fig 3: The impact of optimal PCMs on monthly heating and cooling loads of (a) Tehran, (b) Tabriz, (c) Yazd, (d) Bandar Abbas

\subsection{Impact of optimal PCM on average indoor temperature}

This section discusses the effect of PCM on the highest and lowest average indoor temperatures in the hottest and coldest months of the year, which in all cities, are Jan and Jul, respectively. As shown in Fig. 4a, in Tehran, the difference between the highest and lowest average indoor temperatures without $\mathrm{PCM}$ is $33.5^{\circ} \mathrm{C}$, but can be reduced to $22.5^{\circ} \mathrm{C}$ by the use of $\mathrm{PCM}-29^{\circ} \mathrm{C}$. The use of this $\mathrm{PCM}$ leads to a $3.8^{\circ} \mathrm{C}$ decrease in this temperature difference in Jul. This PCM also reduces the average maximum indoor temperature in the hottest month by $1.9^{\circ} \mathrm{C}$ and increases the average minimum indoor temperature in the coldest month by $3.2^{\circ} \mathrm{C}$. For the city of Tabriz (Fig. 4b), the use of PCM $-19^{\circ} \mathrm{C}$ leads to a $2.9^{\circ} \mathrm{C}$ and $3{ }^{\circ} \mathrm{C}$ reduction in the difference between the average maximum and minimum temperatures in Jan and Jul respectively. The lowest impact of PCM on the maximum and minimum indoor 
temperatures $\left(1.6^{\circ} \mathrm{C}\right.$ decrease in the average maximum temperature in $\mathrm{Jul}$ and $1{ }^{\circ} \mathrm{C}$ increase in the average minimum temperature in Jan) is seen in this city. The cause of this limited impact is the cold winters and hot summers of this city, when air temperatures are usually beyond the functional range of PCM. In Yazd (Fig. 4c), using PCM $-29^{\circ} \mathrm{C}$ results in $2{ }^{\circ} \mathrm{C}$ decrease in the average maximum temperature in $\mathrm{Jul}$ and a $2.5^{\circ} \mathrm{C}$ increase in the average minimum temperature in Jan. As shown in Fig. 4d, the use of PCM in the port city of Bandar Abbas decreases the average maximum temperature and increases the average minimum temperature in the hottest and coldest months by $4.7^{\circ} \mathrm{C}$ and $7.7^{\circ} \mathrm{C}$ respectively. Although the impact of PCM in this city is related to a rather short period, the convenient match between average outdoor temperature during this period and the phase change temperature of PCM amplifies the effect. Taken together, in all climates, the utilization of PCMs reduces average maximum temperatures; and also ameliorates average minimum temperatures, but the results vary according to the climate and PCM types. That is, the closer the air temperature is to the functional range of PCMs, the higher the indoor improvement can be attained.

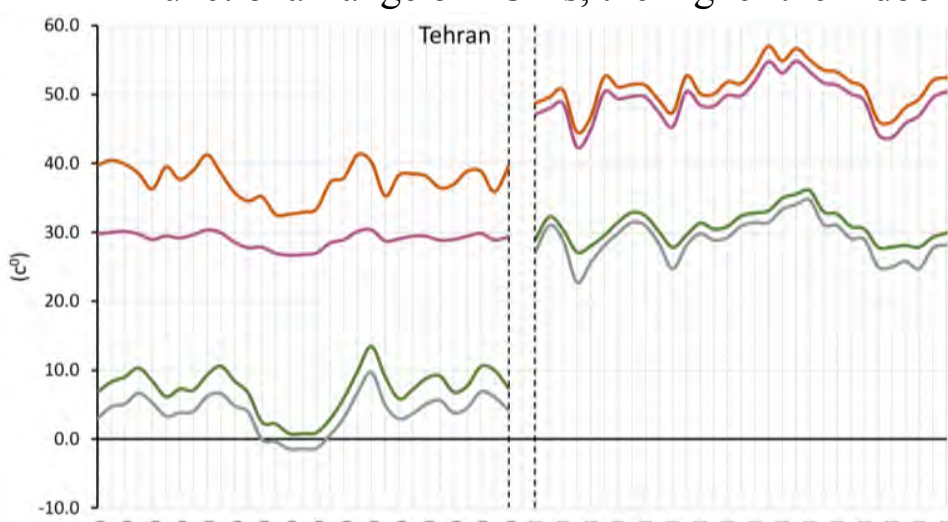

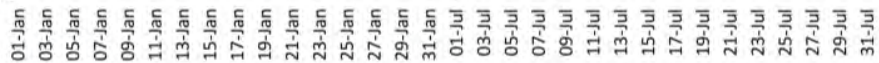

Mean max air temperatures $\quad$ Mean max air temperatures with $\mathrm{PCM}$

- Mean min air temperatures _- Mean min air temperatures with $\mathrm{PCM}$

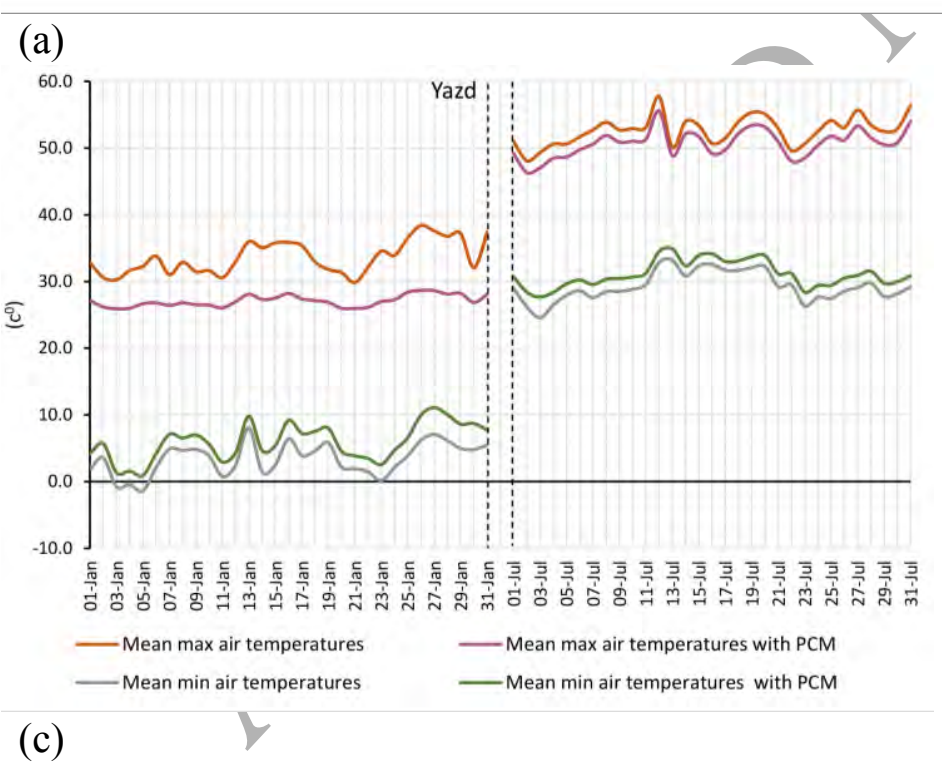

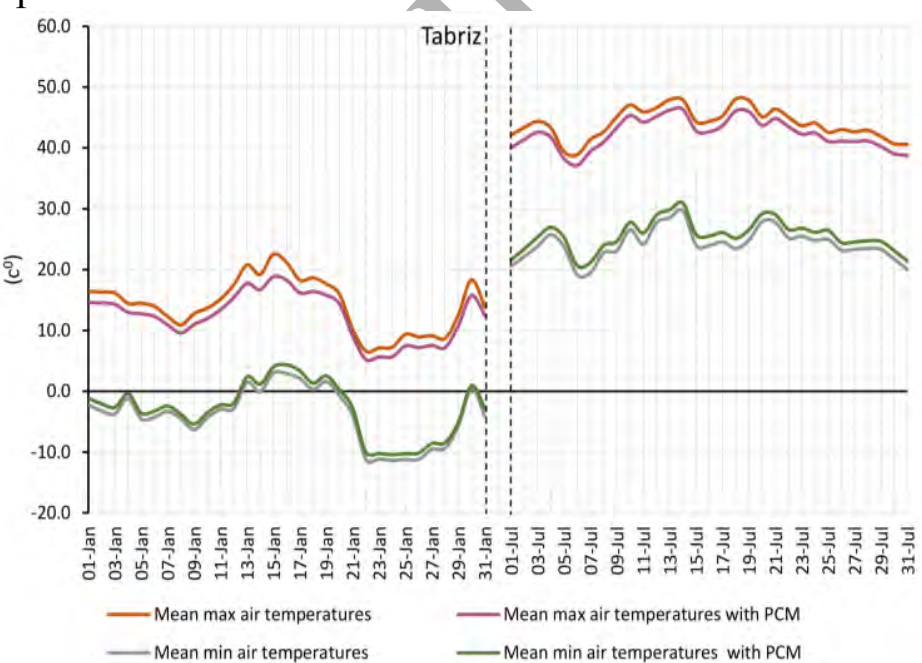

(b)

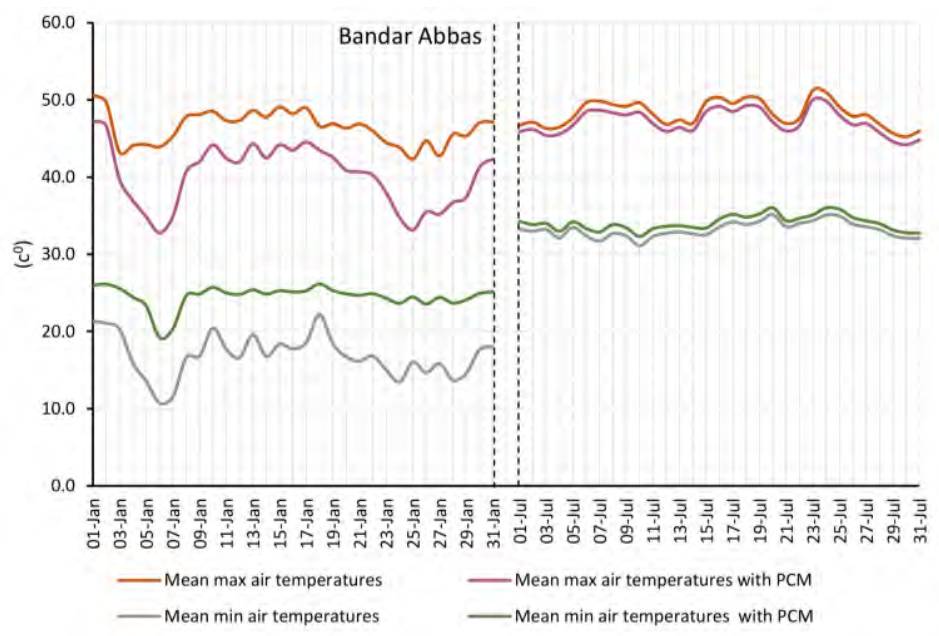

(d)

Fig 4: The impact of optimal PCMs on average indoor temperature of (a) Tehran, (b) Tabriz, (c) Yazd, (d) Bandar Abbas 


\subsection{Economic analysis}

\subsubsection{Effect of PCM on cooling cost (electricity bills)}

This section investigates the impact of optimal PCMs in the cooling cost or electricity consumption in the studied cities. In Iran, electricity is billed based on the increasing block tariff (IBT), with the blocks adjusted for different climates so that warmer regions have access to cheaper electricity during hotter months (Table 2). According to the classification of Iran's Ministry of Energy [49], Bandar Abbas belongs to the category of Hot Regions (1) and has 9 hot months with cheaper electricity (Mar to Nov). According to the same classification, Yazd belongs to the category of Hot Regions (2) and has six hot months with cheaper electricity (Apr to Oct). The tariffs for the remaining months of these two cities and all months of Tehran and Tabriz are calculated based on the normal rates of IBT.

Table 2. Electricity tariffs for different regions and periods [49]

\begin{tabular}{|c|c|c|c|c|c|c|c|c|c|}
\hline $\begin{array}{l}\text { Average monthly energy consumption } \\
\text { (kWh per month) }\end{array}$ & $0-100$ & $100-200$ & $200-300$ & $300-400$ & $400-500$ & $500-600$ & $>600$ & High Peak & $\begin{array}{l}\text { Off- } \\
\text { peak }\end{array}$ \\
\hline $\begin{array}{l}\text { Tariffs for normal regions and non- hot } \\
\text { months } \\
\text { Base price per kilowatt hour (Rials) }\end{array}$ & 450 & 525 & 1125 & 2025 & 2325 & 2926 & 3226 & 450 & 225 \\
\hline $\begin{array}{l}\text { Tariffs for warm months in Hot Regions (1) } \\
\text { Base price per kilowatt hour (Rials) }\end{array}$ & 150 & 166 & 180 & 750 & & & 2025 & 150 & 75 \\
\hline $\begin{array}{l}\text { Tariffs for warm months in Hot Regions (2) } \\
\text { Base price per kilowatt hour (Rials) }\end{array}$ & 330 & 750 & 1275 & & & 2025 & 2176 & 300 & 150 \\
\hline $\begin{array}{l}\text { Tariffs for warm months in Hot Regions (3) } \\
\text { Base price per kilowatt hour (Rials) }\end{array}$ & 375 & 976 & & & 2025 & 2176 & 2325 & 300 & 150 \\
\hline $\begin{array}{l}\text { Tariffs for warm months in Hot Regions (4) } \\
\text { Base price per kilowatt hour (Rials) }\end{array}$ & 361 & 421 & & 1200 & 1726 & 2251 & 2701 & 300 & 150 \\
\hline
\end{tabular}

In general, the energy cost is calculated in three classes: medium-peak (7:00-19:00), highpeak (19:00-23:00), and off-peak (23:00-7:00), the relevant rates of in the year 2017 are listed in Table 2. It should be noted that the medium-peak bill is calculated based on the listed blocks, and the total energy bill is equal to the sum of high-peak and medium-peak bills minus the off-peak bill. The energy consumption estimates in the presence and absence of PCM in the studied eities based on the above tariffs are given in Table 3. As can be seen, the use of PCM has reduced the cooling load of Bandar Abbas by $10 \%$, but because of subsidized electricity consumption in this hot region, the corresponding decrease in the electricity bill is $33 \%$. In contrast, in Tabriz, where there is no such subsidy and the use of PCM has decreased the cooling load by $15 \%$, the decrease in the electricity bill is only $17 \%$. In both Tehran and Yazd, the use of PCM has resulted in a $28 \%$ reduction in the cooling load. However, while the subsidized electricity bill in Yazd has decreased by $42 \%$, the unsubsidized electricity bill in Tehran has reduced by $31 \%$. In all cities, the use of PCM has significantly decreased the medium-peak, off-peak, and as such total electricity bills, but has resulted in a 1.5 times increase in the high-peak bill. The cause of this increase is that the use of PCMs has encouraged the shift of consumption towards peak hours. 
Table 3. Economic analysis of cooling cost with and without PCMs

\begin{tabular}{|c|c|c|c|c|c|c|c|c|c|}
\hline & & $\begin{array}{c}\text { Total } \\
\text { cooling } \\
\text { load } \\
(\mathrm{kWh})\end{array}$ & $\begin{array}{c}\text { Total } \\
\text { consumption } \\
\text { during medium- } \\
\text { peak hours } \\
(\mathrm{kWh}) \\
\end{array}$ & $\begin{array}{c}\text { Total bill of } \\
\text { medium-peak } \\
\text { consumption } \\
\text { (Rial) }\end{array}$ & $\begin{array}{c}\text { Total } \\
\text { consumption } \\
\text { during high- } \\
\text { peak hours } \\
(\mathbf{k W h}) \\
\end{array}$ & $\begin{array}{c}\text { Total bill of } \\
\text { high-peak } \\
\text { consumption } \\
\text { (Rial) }\end{array}$ & $\begin{array}{c}\text { Total } \\
\text { consumption } \\
\text { during off- } \\
\text { peak hours } \\
(\mathbf{k W h}) \\
\end{array}$ & $\begin{array}{c}\text { Total bill of } \\
\text { off-peak } \\
\text { consumption } \\
\text { (Rial) }\end{array}$ & Total IRR \\
\hline \multirow[t]{2}{*}{ Tehran } & $\begin{array}{l}\text { without } \\
\text { PCM }\end{array}$ & 7002.9 & 6858.6 & 12033678.0 & 129.6 & 58314.2 & 14.8 & 3324.3 & 12088668.0 \\
\hline & PCM29 & 5017.1 & 4768.5 & 8317905.4 & 195.0 & 87769.7 & 53.6 & 12051.3 & 8393623.8 \\
\hline \multirow[t]{2}{*}{ Tabriz } & $\begin{array}{l}\text { without } \\
\text { PCM }\end{array}$ & 2497.6 & 2447.5 & 2766475.7 & 49.9 & 22450.0 & 0.2 & 39.5 & 2788886.2 \\
\hline & PCM19 & 2115.7 & 2042.3 & 2281670.5 & 73.0 & 32835.2 & 0.5 & 102.1 & 2314403.6 \\
\hline \multirow[t]{2}{*}{ Yazd } & $\begin{array}{l}\text { without } \\
\text { PCM }\end{array}$ & 6638.3 & 6418.0 & 3132368.3 & 192.0 & 57587.6 & & 4251.5 & 3185704.4 \\
\hline & PCM29 & 4837.6 & 4509.7 & 1786196.6 & 262.9 & 78856.1 & & 9755.1 & 1855297.7 \\
\hline \multirow[t]{2}{*}{$\begin{array}{c}\text { Bandar } \\
\text { Abbas }\end{array}$} & $\begin{array}{l}\text { without } \\
\text { PCM }\end{array}$ & 10185.7 & 9178.5 & 4365079.9 & 531.2 & & & 35704.9 & 4409052.9 \\
\hline & PCM27 & 9207.6 & 7190.0 & 2889835.0 & 931.6 & & 1086.0 & 81450.0 & 2948121.3 \\
\hline
\end{tabular}

\subsubsection{Effect of $P C M$ on heating cost (natural gas bills)}

In Iran, buildings are heated by natural gas. Like electricity, natural gas is billed based on IBT, with the blocks adjusted to subsidize cold regions during cold months (Nov 7 to Apr 4). In the remaining months of the year (Apr 5 to Nov 6), the price of gas in all regions is calculated according to the normal rates of IBT (Table 4). According to the National Iranian Gas Company [36], gas bills are calculated based on the four climates. In the case of cities considered in this paper, Tabriz belongs to Climate No. 1, Yazd and Tehran are located in Climate No. 3, and Bandar Abbas belongs to Climate No. 4. As shown in Table 5, the cold climate of Tabriz results in it having the highest heating cost (183096 Rials) among the four cities. The use of PCMs reduces the annual heating load of this city by $22 \%$, thereby decreasing the heating cost by $27 \%$ to 134250 Rials. In Bandar Abbas, PCMs eliminates the already negligible heating cost (5910 Rials). In Yazd and Tehran, where the heating cost is almost the same (68630 and 74871 Rials, respectively), the use of PCMs reduces the heating cost by about $52 \%$ (unlike the case of electricity, the two cities receive the same subsidy on the gas bill). Overall, with the effect of subsidies taken into account, the highest impact of PCM on the heating costs will be seen in Tabriz (48846 Rials), Tehran (41970 Rials), Yazd (37093 Rials) and Bandar Abbas (5918 Rials) in that order. 
Table 4. Natural gas tariffs for the household sector [50]

\begin{tabular}{|c|c|c|c|c|c|c|c|c|c|c|c|c|}
\hline \multicolumn{13}{|c|}{ During the cold period (climate adjusted-IBT) } \\
\hline Consumption Block & 1st & 2nd & 3rd & 4th & 5th & 6th & 7th & 8th & \multicolumn{3}{|c|}{ 11th } & $\overline{12 \text { th }}$ \\
\hline $\begin{array}{c}\text { Consumption volume }\left(\mathrm{m}^{3}\right) \\
\text { Climate }(1)\end{array}$ & $<300$ & $301-400$ & $401-500$ & $501-600$ & $601-700$ & $701-800$ & $801-900$ & $901-1000$ & $1101-1200$ & \multicolumn{2}{|c|}{$1201-1300$} & $>1300$ \\
\hline $\begin{array}{l}\text { Consumption volume }\left(\mathrm{m}^{3}\right) \\
\text { Climate }(2)\end{array}$ & $<250$ & $251-350$ & $351-450$ & $451-550$ & $551-650$ & $651-750$ & $751-850$ & & $1051-1150$ & \multicolumn{2}{|c|}{$1151-1250$} & $>1250$ \\
\hline $\begin{array}{c}\text { Consumption volume }\left(\mathrm{m}^{3}\right) \\
\text { Climate }(3)\end{array}$ & $<200$ & $201-300$ & $301-400$ & $401-500$ & $501-600$ & $601-700$ & $701-800$ & & $1001-1100$ & \multicolumn{2}{|c|}{$1101-1200$} & $>1200$ \\
\hline $\begin{array}{l}\text { Consumption volume }\left(\mathrm{m}^{3}\right) \\
\text { Climate (4) }\end{array}$ & $<150$ & $151-250$ & $251-350$ & $351-450$ & $451-550$ & $651-750$ & & & $951-1050$ & \multicolumn{2}{|c|}{$1051-1150$} & $>1150$ \\
\hline 2017 Price $\left(\right.$ Rials $\left./ \mathrm{m}^{3}\right)$ & 410 & 690 & 960 & 1240 & 1510 & 2200 & & -3030 & 3860 & \multicolumn{2}{|c|}{441} & 483 \\
\hline \multicolumn{13}{|c|}{ During the warm period (IBT) } \\
\hline Consumption Block & 1st & 2nd & 3rd & 4th & 5th & & 7 th & 8th & 10th & \multicolumn{2}{|l|}{ 11th } & 12th \\
\hline Consumption volume $\left(\mathrm{m}^{3}\right)$ & $<45$ & $45-95$ & $96-145$ & $146-195$ & & & $296-345$ & 346-395 & $446-495$ & \multicolumn{2}{|c|}{$496-545$} & $>545$ \\
\hline 2017 Price (Rials $/ \mathrm{m}^{3}$ ) & 1080 & 1310 & 1650 & 2110 & & 2800 & 3150 & 3490 & 3950 & \multicolumn{2}{|c|}{418} & 430 \\
\hline & \multicolumn{3}{|c|}{ Tehran } & & \multicolumn{3}{|c|}{ Tabriz } & & \multicolumn{4}{|c|}{ Bandar Abbas } \\
\hline Natural gas & \multicolumn{2}{|c|}{ Without PCM } & & & & \multicolumn{2}{|c|}{ PCM19 } & Without PCM & \multicolumn{2}{|c|}{ Without PCM } & \multicolumn{2}{|c|}{$\mathrm{PCM} 27$} \\
\hline Heating Energy [kWh](Hourly) & & 827.8 & & & 4218.6 & \multicolumn{2}{|c|}{3278.6} & 1693.7 & \multicolumn{2}{|c|}{151.9} & \multicolumn{2}{|c|}{0.0} \\
\hline Total cost (IRR) & & 71 & & & 183096 & \multicolumn{2}{|c|}{134250} & 68630 & \multicolumn{2}{|c|}{5918} & \multicolumn{2}{|c|}{0.0} \\
\hline
\end{tabular}




\subsubsection{Effect of PCMs on total energy cost}

To conduct the economic evaluation, this research utilizes the Static Payback Period (SPP) method. The method considers the project construction commencement date and the project annual net income, which is the subtraction of annual expenditure from annual income. Due to its simplicity, this method has been employed in many technical economic analyses. For PCM application, the SPP is given by the following equation [37].

$\mathrm{SPP}=\frac{\mathrm{C}_{\mathrm{pcm}}}{\mathrm{S}}$

Where SPP is a static payback period, $\mathbf{C}_{\mathbf{P C M}}$ is the extra initial investment for PCM application, and $\mathbf{S}$ is the income generated from energy saving. Assuming that each square meter of PCM costs 38.58 USD [46], based on Eq. (1) and the energy cost sayings listed in Table 6, the use of PCMs in Tehran, Tabriz, Yazd, and Bandar Abbas will have a payback period of 42, 179, 102 and 114 years respectively. As a consequence, in the Iranian construction industry with a 30 year common service life of buildings [51], the use of these materials in not cost-effective. As illustrated, the amount of energy saving in Tehran and Yazd are approximately the same; however, the SPP of Yazd due to its economic subsidy is more than double that of Tehran. Similarly, owing to subsidy the SPP for Tabriz and Bandar Abbas, which have almost the same amount of energy saving, is high; however, since generally the gas price is lower than electricity, the SPP of the heating dominant climate of Tabriz is 65 years more than Bandar Abbas. Therefore, in a best-case scenario, Tehran with the highest energy saving and the lowest subsidy has 42 years payback period, which is still higher than the common service life of buildings in Iran.

Overall, there is an inverse relation between energy subsidies and the return period of the PCM capital cost. Because the higher the energy subsidy is, the lower the cost of energy in the demand section and the amount of energy savings is gained, thereby increasing the return period of the investment. Evidently, regarding economic feasibility, the combination of high capital cost of PCMs with low energy prices is the crucial deterrent to the successful deployment of PCM in residential buildings of Iran. Thus, with increasing energy rates and possible decreasing PCM costs, future investment stimulus might be economically viable.

\begin{tabular}{lcccc} 
& & & \\
Table 6. Economic analysis of PCM application & & & \\
\hline City & Tehran & Tabriz & Yazd & BandarAbbas \\
\hline Energy savings (kWh) & 2969.65 & 1321.85 & 2684.71 & 1128.10 \\
Energy savings (Rial) & 4114740 & 962940 & 1701330 & 1519340 \\
SPP (Year) & 42 & 179 & 102 & 114 \\
\hline
\end{tabular}




\subsection{Discussion}

The main goal of this study was to investigate the feasibility of utilizing PCMs in residential buildings of four different Iranian climates, by taking into account their total energy saving, as well as economic efficiency. Many studies have been carried out in this subject and these climates [30, 38, 52-54], and are summarized in Table 7 to compare their results with those of this study.

Table 7. Optimum PCM peak melting temperature for total annual energy consumption [30, 52-55]

\begin{tabular}{clccc}
\hline Climate zones & \multicolumn{1}{c}{ Cities } & $\begin{array}{c}\text { Optimum melting point for } \\
\text { heating and cooling }\end{array}$ & Total heating \& cooling savings \\
& & $\left({ }^{\circ} \mathrm{C}\right)$ & $(\mathrm{kWh})$ & $(\%)$ \\
\hline \multirow{2}{*}{ Csa } & Seville (Spain) & 26.0 & 811 & 3.5 \\
& Cagliari (Italy) & 26.0 & 450 & 1.7 \\
\hline \multirow{3}{*}{ BSk } & Albuquerque (USA) & 20.0 & 1381 & 2.5 \\
& Midland (USA) & 20.0 & 1300 & 3.0 \\
& Ceduna (Australia) & 25.0 & 317 & 7.3 \\
\hline \multirow{3}{*}{ BWk } & Calama (Chile) & 25.6 & 1018 & 2.6 \\
& Las Vegas (USA) & 26.0 & 5213 & 3.3 \\
\hline \multirow{3}{*}{ BWh } & Yumenzhen (China) & 26.0 & 975 & 1.8 \\
& Abu Dhabi (UAE) & 26.0 & 770 & 1.4 \\
& Jaisalmer (India) & 25.9 & 1018 & 2.7 \\
\hline
\end{tabular}

The main reason for the differences in PCM transition temperatures is the variety of HVAC thermostat control set-points for various standards in different countries. That is, for the climates of Csa, BWk, and BSk and considering the cooling/heating set-point of 21 and $28^{\circ} \mathrm{C}$ in our research, the optimal PCM transition temperatures were $19^{\circ} \mathrm{C}$ and $29^{\circ} \mathrm{C}$ for dominant heating and dominant cooling load demand climates, respectively. However, as shown in Table 7 , prior studies have noted that in the same climates but with different HVAC setpoints (the set-point for cooling and heating is $20^{\circ} \mathrm{C}$ and $26^{\circ} \mathrm{C}$ ), so the optimum PCM transition temperatures for dominant heating and cooling load demand climates were $20^{\circ} \mathrm{C}$ and $26^{\circ} \mathrm{C}$, respectively. In this table, since the HVAC set-point for the $\mathrm{BWh}$ climate is the same as other climates, $\mathrm{PCM}-26^{\circ} \mathrm{C}$ was optimal; however, as in Bandar Abbas the cooling set-point is $25^{\circ} \mathrm{C}, \mathrm{PCM}-27^{\circ} \mathrm{C}$ was optimal; resulting overall in reinforcing the significance of HVAC set-points along with climate types in defining the optimal PCM transition temperature. Additionally, the noticeable difference in energy conversion for similar climates is mainly related to the duration of simulations or experiments (daily, monthly or annually), the calculated area of the model, the thickness of PCMs, and the thermal characteristics of the insulation. Naturally, factors such as sunshine, wind characteristic, precipitation intensity, amount of cloud cover, daily temperature, altitude, and relative humidity are also important, and are not considered in the Koppen-Geiger climate classification [53, 54].

Indoor air temperature is also one of the factors which influences the integration of PCMs in a building - in this case, decreasing in warm months and increasing in cold months - and is usually evaluated in two ways: average indoor air temperatures and peak indoor air temperatures $[12,56,57]$. For example, due to the use of PCMs in a building in Algiers (Csa), the average indoor temperature and peak indoor temperature increased by $1.5^{\circ} \mathrm{C}$ and $1{ }^{\circ} \mathrm{C}$ in winter, and dropped by $8.5^{\circ} \mathrm{C}$ and $9{ }^{\circ} \mathrm{C}$ in summer, respectively [58]. This study confirms the improvement of indoor temperature in all climates; however, the amount of 
improvement differed according to the varying climate. That is, for the climate where the indoor temperature is mainly in the range of PCM transition temperature, the application of these materials can have a remarkable impact on either reducing indoor temperature in hot months or increasing it in cold moths. However, for the climates where the indoor temperature mainly goes beyond the PCM functional temperature, the productive effect of PCMs dwindled. In these climates in order to optimize PCMs, the application of supplementary energy efficient techniques such as night ventilation can be productive [59, $60]$.

The main factors in the economic assessment of utilizing phase change materials are gas tariffs, electricity tariffs, capital cost of PCMs, and bank interest [14, 21, 23-33], and considering these factors the resultant payback periods vary for different cities. For instance, the PCM payback period for the city of Shenzhen was 11 years [39], which is shorter than its building average life span (60 years), the use of PCMs is thus cost effective. Likewise, in the cities of Atlanta, Bakersfield, Fort Worth, Miami and Phoenix, the payback period was estimated at 7-10 years [41]. However, in Iran, in the best scenario, the payback period of using PCMs was 42 years, which is more that its common building servíce. Thus, despite considerable improvement in total energy conservation and indoor thermal conditions, the use of PCMs in Iran is uneconomical due mainly to low energy tariffs, high capital cost of these materials, and subsidy.

\section{Conclusion}

This study set out to examine the effect of PCMs on energy consumption, conservation, cost, and indoor temperature conditions in different climates of Iran. Results showed that the optimal PCMs melting temperature to be used was contingent upon both HVAC set-point temperatures and climate conditions. As such for the climates where their defined set-point for heating and cooling was 20 and $28^{\circ} \mathrm{C}, \mathrm{PCM}-19^{\circ} \mathrm{C}$ and $\mathrm{PCM}-29^{\circ} \mathrm{C}$ respectively were optimal for reducing heating loads of cold climates and cooling loads of hot climates. However, for hot-humid climates, where the defined set-point was $20-25^{\circ} \mathrm{C}, \mathrm{PCM}-27^{\circ} \mathrm{C}$ was optimal. The greatest impact of PCMs on annual energy consumption was a 34\% reduction obtained for Tehran (Csa) and a 32.2\% reduction calculated for Yazd (BWk), and the smallest was a $10.9 \%$ reduction obtained for Bandar Abbas (BWh). The main reason for this low efficacy of PCMs in reducing cooling loads of the hot-humid climate was due to the prevention of PCMs from losing stored heat during hot nights, and the consequent failure of the solidifying process. However, in hot dry climates owing to cold nights in summer, PCMs could be solidified, thereby maximizing the PCM potential in reducing cooling loads.

Investigation of the impacts of PCMs during the hottest and coldest months of the year showed that in the hot climates, the use of PCM was not as effective during hot months, and in the cold climates, the use was not as effective during cold months of the year. This is because during these months, the average temperature was usually beyond the range of PCM transition temperatures. However, for moderate months that had average temperatures within the range of PCM functional temperatures, the energy saving was remarkable. Thus, climates with more moderate conditions can benefit more from the deployment of PCM.

In all climates, the use of PCMs respectively reduced and increased the maximum and minimum average temperatures, which meant a less fluctuating and more balanced indoor 
temperature could be achieved, but the results varied according to the climate and PCM types. That is, the closer the air temperature is to the functional range of PCMs, the greater the improvement in indoor temperature can be attained. Additionally, in spite of increasing high-peak cost in all cities, the use of PCMs led to dramatically reduced off-peak, mediumpeak, and as such total electricity costs. Based on the 2017 prices of energy carriers and PCMs, in the case of using PCMs, the corresponding payback periods for Tehran, Tabriz, Yazd, and Bandar Abbas, due to current inexpensive energy tariffs along with subsidies, and the high price of these materials were found to be 42,179, 102, and 114 years, respectively, which renders the use of these materials in the Iranian construction industry with 30 years common service life uneconomical.

\section{References}

[1] U. EIA, "Energy Information Administration "International Energy Outlook"," report DOE/EIA-04842016.

[2] M. LaFrance, "Technology Roadmap: Energy efficient building envelopes," in Energy Technol. Pol. Div.: IEA, 2013.

[3] S. B. Sadineni, S. Madala, and R. F. Boehm, "Passive building energy savings: A review of building envelope components," Renewable and Sustainable Energy Reviews, vol. 15, no. 8, pp. 3617-3631, 2011.

[4] E. Shaviv, A. Yezioro, and I. G. Capeluto, "Thermal mass and night ventilation as passive cooling design strategy," Renewable energy, vol. 24, no. 3, pp. 445-452, 2001.

[5] B. Givoni, "Comfort, climate analysis and building design guidelines," Energy and buildings, vol. 18, no. 1, pp. 11-23,1992.

[6] F. H. Mallick, "Thermal comfort and building design in the tropical climates," Energy and buildings, vol. 23, no. 3, pp. 161-167, 1996.

[7] F. Fazlikhani, H. Goudarzi, and E. Solgi, "Numerical analysis of the efficiency of earth to air heat exchange systems in cold and hot-arid climates," Energy Conversion and Management, vol. 148, pp. 78-89, 2017.

[8] S. Verbeke and A. Audenaert, "Thermal inertia in buildings: A review of impacts across climate and building use," Renewable and Sustainable Energy Reviews, 2017.

[9] M. Saffari, A. de Gracia, S. Ushak, and L. F. Cabeza, "Passive cooling of buildings with phase change materials using whole-building energy simulation tools: A review," Renewable and Sustainable Energy Reviews, vol. 80, pp. 1239-1255, 2017.

[10] D. Zhou, C.-Y. Zhao, and Y. Tian, "Review on thermal energy storage with phase change materials (PCMs) in building applications," Applied energy, vol. 92, pp. 593$605,2012$.

[11] B. Xu and Z. Li, "Paraffin/diatomite composite phase change material incorporated cement-based composite for thermal energy storage," Applied energy, vol. 105, pp. 229-237, 2013.

[12] E. Solgi, B. M. Kari, R. Fayaz, and H. Taheri, "The impact of phase change materials assisted night purge ventilation on the indoor thermal conditions of office buildings in hot-arid climates," Energy and Buildings, 2017.

[13] B. Xu, H. Ma, Z. Lu, and Z. Li, "Paraffin/expanded vermiculite composite phase change material as aggregate for developing lightweight thermal energy storage cement-based composites," Applied Energy, vol. 160, pp. 358-367, 2015.

[14] S. Memarian, B. Mohammad Kari, R. Fayaz, and S. Asadi, "The Impact of Phase 
Change Materials (PCM) on the Duration of Spring and Autumn Transitional periods in Residential Buildings," Scientific Journal Management System, vol. 10, no. 19, pp. 39-60, 2017.

[15] S. Memarian, "Studying Factors Affecting the Duration of Seasonal Transition Period in Residential Buildings," Master, Faculty of Architecture and Urbanism, University of Arts, 2016.

[16] A. de Gracia and L. F. Cabeza, "Phase change materials and thermal energy storage for buildings," Energy and Buildings, vol. 103, pp. 414-419, 2015.

[17] E. Solgi, B. Mohammad Kari, R. Fayaz, B. Hoseini, and H. Taheri, "Enhancing the Performance of Night Ventilation Systems in Office Buildings Using Phase Change Materials, Case Study in Yazd," Armanshahr Architecture \& Urban Development, vol. 9, no. 17, pp. 53-62, 2017.

[18] N. P. Sharifi, A. A. N. Shaikh, and A. R. Sakulich, "Application of phase change materials in gypsum boards to meet building energy conservation goals," Energy and Buildings, vol. 138, pp. 455-467, 2017.

[19] M. Esen and T. Ayhan, "Development of a model compatible with solar assisted cylindrical energy storage tank and variation of stored energy with time for different phase change materials," Energy Conversion and Management, vol. 37, no. 12, pp. 1775-1785, 1996.

[20] M. Esen, A. Durmuş, and A. Durmuş, "Geometric design of solar-aided latent heat store depending on various parameters and phase change materials," Solar energy, vol. 62 , no. 1 , pp. 19-28, 1998.

[21] M. Esen, "Thermal performance of a solar-aided latent heat store used for space heating by heat pump," Solar energy, vol. 69, no. 1, pp. 15-25, 2000.

[22] M. Esen and T. Yuksel, "Experimental evaluation of using various renewable energy sources for heating a greenhouse," Energy and Buildings, vol. 65, pp. 340-351, 2013.

[23] H. Esen, M. Inalli, and M. Esen, "Technoeconomic appraisal of a ground source heat pump system for a heating season in eastern Turkey," Energy Conversion and Management, vol. 47, no, 9-10, pp. 1281-1297, 2006.

[24] H. Esen, M. Inalli, and M. Esen, "A techno-economic comparison of ground-coupled and air-coupled heat pump system for space cooling," Building and environment, vol. 42, no. 5, pp. 1955-1965, 2007.

[25] D. Zhou, G. Shire, and Y. Tian, "Parametric analysis of influencing factors in Phase Change Material Wallboard (PCMW)," Applied Energy, vol. 119, pp. 33-42, 2014.

[26] F. Ascione, N. Bianco, R. F. De Masi, F. de’Rossi, and G. P. Vanoli, "Energy refurbishment of existing buildings through the use of phase change materials: Energy savings and indoor comfort in the cooling season," Applied Energy, vol. 113, pp. 9901007, 2014.

[27] J. Lei, J. Yang, and E.-H. Yang, "Energy performance of building envelopes integrated with phase change materials for cooling load reduction in tropical Singapore," Applied Energy, vol. 162, pp. 207-217, 2016.

[28] X. Jin and X. Zhang, "Thermal analysis of a double layer phase change material floor," Applied Thermal Engineering, vol. 31, no. 10, pp. 1576-1581, 2011.

[29] M. Kenisarin and K. Mahkamov, "Passive thermal control in residential buildings using phase change materials," Renewable and sustainable energy reviews, vol. 55, pp. 371-398, 2016.

[30] M. Saffari, A. de Gracia, C. Fernández, and L. F. Cabeza, "Simulation-based optimization of PCM melting temperature to improve the energy performance in buildings," Applied Energy, vol. 202, pp. 420-434, 2017.

[31] M. Saffari, A. de Gracia, S. Ushak, and L. F. Cabeza, "Economic impact of 
integrating PCM as passive system in buildings using Fanger comfort model," Energy and Buildings, vol. 112, pp. 159-172, 2016.

[32] R. Barzin, J. J. Chen, B. R. Young, and M. M. Farid, "Application of PCM energy storage in combination with night ventilation for space cooling," Applied Energy, vol. 158, pp. 412-421, 2015.

[33] R. Barzin, J. J. Chen, B. R. Young, and M. M. Farid, "Application of weather forecast in conjunction with price-based method for PCM solar passive buildings-An experimental study," Applied Energy, vol. 163, pp. 9-18, 2016.

[34] N. Zhu, S. Wang, Z. Ma, and Y. Sun, "Energy performance and optimal control of airconditioned buildings with envelopes enhanced by phase change materials," Energy Conversion and Management, vol. 52, no. 10, pp. 3197-3205, 2011.

[35] A. Chan, "Energy and environmental performance of building façades integrated with phase change material in subtropical Hong Kong," Energy and Buildings, vol. 43, no. 10, pp. 2947-2955, 2011.

[36] X. Sun, Q. Zhang, M. A. Medina, and K. O. Lee, "Energy and economic analysis of a building enclosure outfitted with a phase change material board (PCMB)," Energy conversion and Management, vol. 83, pp. 73-78, 2014.

[37] X. Mi, R. Liu, H. Cui, S. A. Memon, F. Xing, and Y. Lo, "Energy and economic analysis of building integrated with PCM in different cities of China," Applied Energy, vol. 175, pp. 324-336, 2016.

[38] L. Shilei, F. Guohui, Z. Neng, and D. Li, "Experimental study and evaluation of latent heat storage in phase change materials wallboards," Energy and buildings, vol. 39, no. 10, pp. 1088-1091, 2007.

[39] X. Shi, S. A. Memon, W. Tang, H. Cui, and F. Xing, "Experimental assessment of position of macro encapsulated phase change material in concrete walls on indoor temperatures and humidity levels," Energy and Buildings, vol. 71, pp. 80-87, 2014.

[40] T. Stovall and J. Tomlinson, "What are the potential benefits of including latent storage in common wallboard?," Journal of Solar Energy Engineering, vol. 117, no. 4, pp. 318-325, 1995.

[41] J. Kosny, N. Shukla, and A. Fallahi, "Cost analysis of simple phase change materialenhanced building envelopes in southern US climates," Fraunhofer CSE, Cambridge, MA (United States) 2013.

[42] K. Peippo, P. Kauranen, and P. Lund, "A multicomponent PCM wall optimized for passive solar heating," Energy and buildings, vol. 17, no. 4, pp. 259-270, 1991.

[43] B. al a, J. M. Mar n, . F. Ca e a, and H. Mehling, "Free-cooling of buildings with phase change materials," International Journal of Refrigeration, vol. 27, no. 8, pp. 839-849, 2004.

[44] S. Memarian, B. M. Kari, R. Fayaz, and S. Asadi, "Single and combined phase change materials: Their effect on seasonal transition period," Energy and Buildings, vol. 169, pp. 453-472, 2018.

[45] A. Standard, "Standard 140-2014: Standard Method of Test for the Evaluation of Building Energy Analysis Computer Programs, ASHRAE," Atlanta, 2014.

[46] H. Breesch, "Natural night ventilation in office buildings: performance evaluation based on simulation, uncertainty and sensitivity analysis," Ghent University, 2006.

[47] Code No. 19: Energy Efficiency, 2011.

[48] Chaharmahal \& Bakhtiari Meteorogical Administration. Available: http://www.chaharmahalmet.ir/

[49] K. Goethals, H. Breesch, and A. Janssens, "Sensitivity analysis of predicted night cooling performance to internal convective heat transfer modelling," Energy and Buildings, vol. 43, no. 9, pp. 2429-2441, 2011. 
[50] H. Breesch and A. Janssens, "Performance evaluation of passive cooling in office buildings based on uncertainty and sensitivity analysis," Solar energy, vol. 84, no. 8, pp. 1453-1467, 2010.

[51] M. D. Saghafi and M. Ahmadi, "A study of adaptable architecture pertinence in Iran," Procedia Engineering, vol. 21, pp. 656-665, 2011.

[52] P. Marin et al., "Energy savings due to the use of PCM for relocatable lightweight buildings passive heating and cooling in different weather conditions," Energy and Buildings, vol. 129, pp. 274-283, 2016.

[53] M. Saffari, A. de Gracia, C. Fernández, G. Zsembinszki, and L. F. Cabeza, "Study on the optimum PCM melting temperature for energy savings in residential buildings worldwide," in IOP Conference Series: Materials Science and Engineering, 2017, vol. 251, no. 1, p. 012113: IOP Publishing.

[54] M. Saffari Tabalvandani, A. d. Gracia Cuesta, C. Fernàndez Camon, and L. F. Cabeza, "Simulation-based optimization of PCM melting temperature to improve the energy performance in buildings," Applied Energy, 2017, vol. 202, p. 420-434, 2017.

[55] Available: https://energy.gov/energysaver/air-conditioning

[56] B. Givoni, "Effectiveness of mass and night ventilation in lowering the indoor daytime temperatures. Part I: 1993 experimental periods," Energy and Buildings, vol. 28, no. 1, pp. 25-32, 1998.

[57] L. F. Cabeza, C. Castellon, M. Nogues, M. Medrano, R. Leppers, and O. Zubillaga, "Use of microencapsulated PCM in concrete walls for energy savings," Energy and buildings, vol. 39, no. 2, pp. 113-119, 2007

[58] L. Derradji, F. B. Errebai, and M. Amara, "Effect of PCM in Improving the Thermal Comfort in Buildings," Energy Procedia, vol. 107, pp. 157-161, 2017.

[59] E. Solgi, R. Fayaz, and B. M. Kari, "Cooling load reduction in office buildings of hotarid climate, combining phase change materials and night purge ventilation," Renewable Energy, vol. 85, pp. 725-731, 2016.

[60] E. Solgi, "Optimizing Thermal Mass in Night Ventilation Master thesis," Faculty of Architecture and Urbanism, Art University, 2014. 